\title{
Inflation Protected Investment Strategies
}

\author{
Mirco Mahlstedt ${ }^{*, \dagger}$ and Rudi Zagst ${ }^{*, \dagger}$ \\ Chair of Mathematical Finance, Technical University of Munich (TUM), Parkring 11, 85748 Garching, Germany \\ * Correspondence: mirco.mahlstedt@tum.de (M.M.); zagst@tum.de (R.Z.); Tel.: +49-89-2891-8789 (M.M.); \\ +49-89-2891-7401 (R.Z.); Fax: +49-89-2891-7407 (M.M. \& R.Z.) \\ $\dagger$ These authors contributed equally to this work.
}

Academic Editor: Alexander Szimayer

Received: 28 December 2015; Accepted: 21 March 2016; Published: 28 March 2016

\begin{abstract}
In this paper, a dynamic inflation-protected investment strategy is presented, which is based on traditional asset classes and Markov-switching models. Different stock market, as well as inflation regimes are identified, and within those regimes, the inflation hedging potential of stocks, bonds, real estate, commodities and gold are investigated. Within each regime, we determine optimal investment portfolios driven by the investment idea of protection from losses due to changing inflation if inflation is rising or high, but decoupling the performance from inflation if inflation is low. The results clearly indicate that these asset classes behave differently in different stock market and inflation regimes. Whereas in the long-run, we agree with the general opinion in the literature that stocks and bonds are a suitable hedge against inflation, we observe for short time horizons that the hedging potential of each asset class, especially of real estate and commodities, depend strongly on the state of the current market environment. Thus, our approach provides a possible explanation for different statements in the literature regarding the inflation hedging properties of these asset classes. A dynamic inflation-protected investment strategy is developed, which combines inflation protection and upside potential. This strategy outperforms standard buy-and-hold strategies, as well as the well-known $\frac{1}{N}$-portfolio.
\end{abstract}

Keywords: Markov-switching models; inflation; investment strategies

\section{Introduction}

Governments all over the world have often used inflation to implicitly reduce their national deficit. Argentina, e.g., repeatedly faced inflationary problems over the last few decades caused by a rapid expansion of the money supply. In the aftermath of the worst global financial crisis (July 2007-June 2009) since the Great Depression, governments worldwide again faced the problem of a rapid increase in national debt due to their costly efforts to prevent a collapse of the world's financial system. After the comprehensive liquidity provisions for all major global financial institutions and the setup of multi-billion economic stimulus packages in order to stabilize the economic situation, countries all over the world significantly increased their fiscal deficit and struggled with their own credit worthiness. While cutting costs, increasing taxes and reducing government spending can often cause dissatisfaction and protests among the population, a further increase of liquidity in the markets by the central banks might be a more comfortable way for governments to implicitly reduce their deficits via the growth of the economy or an increasing inflation rate. However, the topic of inflation is not only subject to governmental bodies. In the context of pension investments with a pre-defined (long-term) target, the consideration of inflationary effects is of particular importance. Traditional defined benefit pension plans transfer inflation risk completely to the employer as he or she assures his or her employee a certain real rate for his or her pension payments. In the case of rising inflation, 
this might lead to considerably increased liabilities. Defined contribution systems, on the other hand, transfer inflation risk from the pension payer to the pension receiver, as the final pension payments only depend on the performance of the underlying pension investment portfolio. In both cases, one party has to bear a significant long-term inflation risk, which can have an enormous impact on the terminal value of the actual pension payments and the liabilities of the company.

Consequently, private investors, as well as investment managers have to develop investment strategies to provide a certain protection against losses in real portfolio value, e.g., [1] focus on an insurance company which sold inflation-linked products to its customers within their defined contribution plans. Therefore, the company wants to hedge the resulting inflation risk with inflation-linked bonds. In a market consisting of a money-market account, a stock and an inflation-linked bond, they develop a strategy to optimally manage the pension fund. However, inflation-linked products usually require investors to pay a certain premium for inflation protection and might even incur losses due to rising interest rates before maturity, e.g., in the case of Treasury Inflation-Protected Securities (TIPS). This is especially true if the rise in interest rates is higher than the increase in inflation. On the other side, the premium for inflation-protected securities has to be paid no matter if inflation rises or not. However, investors have no ambition to pay for inflation protection if inflation is tame. Therefore, the goal of this paper is to develop an investment strategy that decouples its performance from inflation if inflation is low, but dynamically protects the portfolio from losses relative to inflation if inflation is high. To define the investment universe for such an investment strategy, it is important to understand the inflation-hedging properties of the different asset classes. As a measure for this, [2,3] apply the Pearson correlation. The work in [3] uses the concept of cointegration, while [4] focuses on real return variance. A mean-variance criteria is presented in [3]. In this paper, the Pearson correlation and the returns of asset classes are investigated for single assets. On the portfolio level, an optimization problem is introduced, which aims to (super-)replicate inflation. We thus want to outperform the inflation rate when it is low while we want to protect the portfolio against inflation when it is high. A detailed literature overview on the inflation-hedging properties of alternative asset classes is given in Section 2.1.

In an interesting overview, [5] compares the performance of different asset classes, like stocks, bonds, real estate and gold, in different crisis environments, such as, e.g., World War 1 and the time of hyperinflation 1914-1923, the Great Depression 1929-1932, as well as World War 2 and the currency reforms 1939-1948. Remarkably, only gold and most of the time real estate performed well during these periods and are thus predicted as inflation-resistant asset classes for the time after 2010. The work in [6] claims that inflation-hedging qualities of alternative asset classes depend on market circumstances, and [3] achieve different results for the inflation-hedging quality of commodities by including/excluding data of the recent financial crisis in 2008. Against the same background, [7] suggests optimal portfolios for periods of deflation, moderate inflation and high inflation. To separate the stock market into normal and turbulent regimes, [8] use a Markov-switching model in a portfolio optimization context. In case of stock returns, abundant literature on Markov-switching models is available: [9] divide the stock market into bullish and bearish periods; [10] analyze systemic risk; whereas [11] investigate asset correlations in different regimes. Additionally, [12] develop an early warning system for turbulent market periods based on Markov-switching models. Picking up on all of these findings, we will apply a Markov-switching model to distinguish between different stock markets, as well as inflation periods.

In a nutshell, the main contribution of the paper is the development of an investment strategy that decouples its performance from inflation if inflation is low, but dynamically protects the portfolio from losses relative to inflation if inflation is high. With the given motivation, inflation-linked products are excluded, and only the asset classes stocks, bonds, commodities, gold and real estate are considered. Key innovation in this analysis is the use of Markov-switching models for both indicators, the market indicator, as well as inflation. In this view, we extend [12] by adding inflation regimes and [13] by adding a transition state. We fit the model to empirical data and compare the 
proposed investment strategy to a standard $50 \% / 50 \%$ stock-bond portfolio, the $\frac{1}{N}$-portfolio and the regime-dependent mean-variance strategy.

The paper is structured as follows: In Section 2, we give an overview of the inflation-hedging properties of different asset classes as it can be found in the literature. We also describe the data used in this paper. In Section 3, the Markov-switching model is presented, and the results of the separation into different regimes using inflation and S\&P 500 are displayed. The methodology to derive the optimal portfolios and the empirical results for short and long time horizons, as well as a reflection of the statements in the financial literature are shown in Section 4. Finally, Section 5 concludes.

\section{Inflation-Hedging Properties of Different Asset Classes}

Inflation is generally defined as an increase in prices. Because it is impossible to measure the price changes of all available goods, prices of a well-defined basket of goods are usually examined. This basket is supposed to represent the ordinary expenses of citizens in the particular area under observation and forms the basis for the price indices. The proxy of inflation in this paper is the Consumer Price Index All Urban (CPI-U) non-seasonally adjusted in the U.S. This is a straightforward choice, as U.S. Treasury Inflation-Protected Bonds (TIPS) are based on the CPI-U (see [14]). The CPI-U will be our benchmark, which has to be outperformed by a dynamic investment strategy consisting of an allocation of different asset classes. To decide on the universe of assets, we first give a literature overview on the findings of the inflation-hedging properties of different asset classes.

\subsection{Stocks}

Several empirical academic studies established that stocks offer a good inflation protection over longer investment horizons. The work in [15] comes to the conclusion that higher future inflation leads to higher dividends and, thus, to higher stock returns. The work in [16] finds that in the long run, stocks seem to retain their values relative to movements in overall price indices using advances from the theory of cointegration and a reduced form approach. Even if stock returns are negatively correlated with unexpected inflation shocks and only moderately positively related to expected inflation, [17] show that stocks can be a hedge against inflation. Using long-run data for OECD countries, [18] find that nominal equity prices eventually keep pace with movements in the overall price level. However, it may take "an exceedingly long time for this to happen". The work in [19] concludes that stocks in the U.S. turn out to be a perfect inflation hedge in the long run, although results for the U.K. and Germany vary. The work in [2] analyzes the strategic asset allocation for an investor with risky liabilities that are subject to inflation and interest rate risk. They find that stocks show a positive correlation with inflation for investment horizons longer than 25 years, but have no inflation-hedging potential in the short run. Using a simple model of return dynamics, [20] come to the conclusion that inflation is negatively correlated with bond and stock real returns at short horizons, but positively correlated over long horizons. The work in [21] finds a positive relationship between inflation and equities, analyzing ten important emerging stock markets during the 1990s. The supposition of a negative correlation between stock returns and inflation is supported by [22]. The work in [4] examines that this negative correlation would lead to the surprising conclusion that stocks should be sold as a hedge against inflation. Furthermore, this statement is emphasized by [23] arguing that higher inflation leads to less economic activity and, therefore, to lower stock returns. Summarizing the scientific opinions, it can be concluded that stocks work quite well as an inflation hedge over a long horizon, even though there seems to be a negative correlation between stock returns and inflation for shorter time horizons.

\subsection{Bonds}

Another asset class we examine for its inflation-hedging potential is bonds. The work in [24] looks at an immortal (infinite maturity) investor, who has the choice between an asset selection consisting of nominal and real, both long-term and short-term, bonds and equities. Their results show 
that both long-term bonds and equities are important in the hedge portfolio, with nominal bonds becoming more important the higher the risk aversion of the investor. According to [17], expected and realized inflation converge over the long term, expecting a positive long-term correlation between bond returns and changes in inflation. Using a vector autoregressive model for returns, liabilities and macroeconomic state variables, [2] analyze different asset classes. Their results for bonds show that they have good inflation-hedging qualities in the long run, but only poor hedging properties in the short run and, therefore, are important tools, especially for long-term investors with liabilities. The work in [25] shows that for an investor only focusing on long-term inflation-hedging properties, nominal bonds can offer a cost-efficient alternative to investing in inflation-linked securities. All in all, bonds seem to have similar inflation-hedging properties than stocks and also exhibit good inflation-hedging properties over longer periods. However, they do not offer inflation protection in the short term.

\subsection{Commodities}

Commodities are fundamentally different from stocks and bonds, as they are real instead of financial assets. The most important indices describing the evolution of commodity prices are the Dow Jones-AIG Commodity Index, the Standard \& Poor's Goldman Sachs Commodity Index (GSCI) and the Thomson Reuters/Jefferies Commodity Research Bureau (CRB)IX Index. The inflation-hedging property of commodities has been scientifically examined and discussed for quite a long time. The work in [26] suggested that an unleveraged index of commodity futures prices can be used as an inflation hedge for a stock portfolio. The work in [27] shows that adding commodity futures to an existing portfolio composed of stocks and bonds can improve the risk-return trade-off of a portfolio in an inflationary environment. In his examination, [28] compares a variety of investable forms of real assets, such as stocks of commodity producers, commodity futures and real estate. He finds evidence that oil and production-weighted indexes of commodity futures are the prime hedge option in a portfolio. The work in [29] states that commodity futures are positively correlated with inflation, unexpected inflation and changes in expected inflation. Future prices evolve along unexpected inflation as they include information about expected trends in commodity prices. The work in [2] finds that commodity futures have very stable inflation-hedging qualities as they show positive correlation for investment horizons longer than three years. The work in [29] also shows positive correlations between inflation and commodity futures, which increase with the holding period. Furthermore, using a vector autoregressive model and the measures Fisher coefficient, Pearson correlation, hedge ratio and hedging demand, [3] show that commodity futures have a significant ability to hedge against inflation during their investigated period of 1970-2011 in the U.S., particularly for investment horizons of at least one year. Additionally, they highlight commodity futures in the markets energy, industrial metals and live cattle as good inflation hedges. However, they point out that the hedging properties vary over time. This is an additional motivation to apply Markov-switching models to identify different regimes.

Using a vector error-correction model, [30], however, come to the interesting result that effective short-term hedges, such as commodities, may not work over longer periods. The work in [31] argues in the same direction by mentioning stability issues by estimating respective beta values over time and focus on TIPS.

Overall, commodities show a positive correlation to inflation and have the best inflation-hedge properties of all alternative assets. However, concerning the time horizon, short term or long term, the statements in the literature about the inflation-hedging properties of commodities vary, with the majority pointing in favor of long-term horizons.

\subsection{Gold}

In the empirical analysis, we will investigate different asset classes in different inflation, as well as market regimes. We decided to include gold as an individual asset class. This is motivated by 
the fact that the inflation-hedging properties of gold are not only investigated in several studies, but additionally, gold is also considered as a hedge with regard to stocks or bonds. The work in [32] provides an overview of the literature considering gold as a "safe heaven" with respect to stocks or bonds, as well as the literature on inflation-hedging properties of gold. They find that the overall results are mixed, and both hedging properties depend on the considered time period, the momentum, the investigated market, as well as market regimes and differ for short-term and long-term horizons. The authors in [32] themselves apply a time-varying Markov-switching approach and conclude that gold is partially able to hedge against inflation in the long run and that the hedging-properties are regime dependent.

\subsection{Real Estate}

It is generally assumed that real estate is a first-class inflation hedge. Nevertheless, there are also academic voices doubting the inflation-hedging potential of real estate. The author in [28] shows in his analysis of real assets that real estate seems to be a hedge against inflation. The work in [33] examines the inflation-hedging effectiveness of residential, farmland and business real estate. In the single-asset analysis, only residential real estate seems to be a reasonable inflation hedge. On the other hand, different portfolios consisting of all three real estate sub-categories in combination with various other financial assets provide a satisfying performance compared to inflation. Once again, [2] conclude that the term-structure properties of listed real estate are already captured by traditional asset classes, such as stocks and bonds. However, the latter perform better in the long-run. The work in [25] confirms that investing in real estate has attractive inflation-hedging qualities for a long-term investor. In combination with commodities and inflation-linked securities, portfolios can be designed so as to decrease the cost of inflation insurance over the long horizon. The work in [6] argues that direct real estate appears to be the most attractive real-asset investment option for the pre-retirement phase. It shows low volatility and still achieves relatively high growth rates. Using a regression analysis, [34] show that REITreal returns are negatively correlated with the unexpected component of inflation. Therefore, equity and mortgage REIT investments may not provide inflation protection during inflationary periods. Scientific opinions whether real estate is a good inflation hedge diverge significantly. Beside many supporters of the thesis that real estate is a useful inflation hedge, such as $[2,28]$ or $[25,34]$ doubt this thesis.

\subsection{Data}

According to the previous studies stocks, bonds, commodities and real estate were chosen as different asset classes to set up a dynamic inflation-protected investment strategy. We also included gold for its role as a safe haven, especially during crises periods. As we wanted to include the first oil crisis of 1973 in our empirical analysis, the number of available indices was limited for some asset classes. As representative stock index, the SEP 500-Total Return Index, was chosen. For real estate, we selected the US SEP/Case-Shiller Home Price Index 10-City Composite to avoid tampering due to the strong correlation between REIT and stock market returns. The Goldman Sachs Commodity Total Return Index was chosen as the commodity index. Bonds are represented by the SEP/BG Cantor U.S. Treasury Bond Index (TR). Finally, the gold price in USD per troy ounce (USD FX Comp, U\$/Troy Oz) was selected as an indicator for the evolution of the gold price.

For all of these indices, we work with monthly log returns from August 1974 until September 2014. ${ }^{1}$

1 For our empirical analysis, it is necessary to let all indices start at August 1974. Data for the bond index are available since December 1989, for the real estate index since January 1987 and the S\&P 500 total return index since January 1988. Therefore, we performed a back calculation of these three indices via a linear regression, e.g., the bond index is regressed on its available historical data using factors with a longer empirical availability, such as U.S. Treasury Constant Maturities middle rates for 1, 3, 5 and 10 years and the BofA Merrill Lynch U.S. Corporate \& Government Master Index. The resulting linear function and the older data of the factors are used to calculate back the bond index for the times when 


\section{Markov-Switching Model}

The application of Markov-switching models for the analysis of econometric time series started with the work of [35]. Typically, a Markov-switching model can be understood as a stochastic model consisting of various random processes. First, we assume the existence of a Markov chain, which is described by different states and transition probabilities between these states. Usually, a Markov chain cannot be observed directly, but rather indirectly via effects to a second, observable process. The distribution of this second process thereby depends on the state of the Markov chain. The work in [35] interpreted the non-observable Markov chain as the "state of the world". The observable process is usually given in the form of an econometric indicator or a market index. In our case, the observable process is given by the returns of the S\&P 500 price index and the inflation rate, respectively. The "state of the world" may be, e.g., a turbulent or normal market period and a low or high inflationary environment. The dynamics of the stock returns, as well as the inflation rate are described by Markov-switching models. As proposed in [12], we apply a three-state model for the stock returns and the inflation rate. Depending on the unobservable state process $\left(S_{t}\right)_{t=1, \ldots, T}$, with $S_{t} \in\{0,1,2\}$, let the process $\left(r_{t}\right)_{t=1, \ldots, T}$ describe either the inflation rate or the return of the stock market index. $r_{t}$ is assumed to be normally distributed in each regime with regime-dependent mean $\mu_{S_{t}}$ and standard deviation $\sigma_{S_{t}}$, i.e.,

$$
r_{t}=\mu_{S_{t}}+\sigma_{S_{t}} \epsilon_{t}, S_{t} \in\{0,1,2\}
$$

where $\epsilon_{t} \sim N(0,1)$ i.i.d. The process of the unobservable state variable $S_{t}$ is modeled as a time-homogeneous Markov chain with a fixed transition probability matrix $p:=\left(p_{i j}\right)_{i, j \in\{0,1,2\}}$ where $p_{i j}:=\mathbb{P}\left(S_{t}=j \mid S_{t-1}=i\right)$ and $p_{i 1}+p_{i 2}+p_{i 3}=1$. The model is completely determined by the parameter vector $\boldsymbol{\theta}=(p, \mu, \sigma, \delta)$, where $\delta:=\left(\delta_{1}, \delta_{2}, \delta_{3}\right)$ is the initial distribution of the Markov chain with $\delta_{i}:=\mathbb{P}\left(S_{1}=i\right), \mu:=\left(\mu_{1}, \mu_{2}, \mu_{3}\right), \mu_{i} \in \mathbb{R}$, and $\sigma:=\left(\sigma_{1}, \sigma_{2}, \sigma_{3}\right)$, $\sigma_{i}>0, i \in\{1,2,3\}$. For the estimation of the parameter vector $\boldsymbol{\theta}$, we use the findings of [36]. ${ }^{2}$ After the parameters have been estimated, the filtered probabilities:

$$
p_{t}^{j}:=\mathbb{P}\left(S_{t}=j \mid \boldsymbol{r}_{t} ; \hat{\boldsymbol{\theta}}_{t}\right), j \in\{0,1,2\}
$$

of being in a certain state $j$ at a certain point in time $t$ are used to identify the actual state to be the one with the highest probability $p_{t}^{j}$.

Hereby, $\boldsymbol{r}_{t}=\left(r_{1}, \ldots, r_{t}\right)$ contains the information available at time $t$, and $\hat{\boldsymbol{\theta}}_{t}$ is the maximum likelihood estimate of the parameter vector $\theta$ based on this information. At any point in time $t$ these probabilities only depend on the information up to time $t$.

\subsection{Markov-Switching Model for the SEP 500 Index}

In a first step, the inflation rate and the S\&P 500 price index are investigated independently. First, we cite the major findings of [12] for the classification of the S\&P 500 index. At first, they apply a Markov-switching model with two states to the log-returns of the S\&P 500. In doing so, they are able to distinguish between normal (low volatility, positive expected return) and turbulent (high volatility) market phases. The turbulent phase however covers volatile upward and downward movements. Therefore, they include a third state. This is achieved by a multi-step approach in which

it is not available. Accordingly the real estate index is calculated back based on a regression with the U.S. Price Index of new One-Family Houses Under Construction (not seasonally adjusted - nadj), the US-Datastream Real Estate Investment Services (U.S.-DS Real Est Inv,Svs) Price Index and the National Association of Real Estate Investment Trusts (NAREIT) Total Return Index. The total return stock index was calculated back based on a regression with the corresponding S\&P 500 price index.

2 The implementation of the presented Markov-switching model has been performed in R. The package HiddenMarkov (see http://cran.fhcrc.org/web/packages/HiddenMarkov/index.html) applies the Baum-Welch algorithm described in [36]. 
the turbulent periods are split into periods with positive and negative expected return by using a second Markov-switching model. Compared to a direct application of a three-state Markov-switching model, this approach has been shown to be more robust, especially w.r.t. out-of-sample tests. The resulting filtered probabilities are computed on the basis of all of the information available up to time $t$. To illustrate their concept, let $\mathbb{T}=\{1, \ldots, T\}$ and $\mathbb{T}^{D}=\left\{t \in \mathbb{T}: \mathbb{P}\left(\hat{S}_{t}=1 \mid \boldsymbol{r}_{t} ; \hat{\boldsymbol{\theta}}_{t}\right)>0.5\right\}$ denote the complete time set and the times when the market is under distress, i.e., in turbulence. Correspondingly, let $\left(\hat{S}_{t}\right)_{t \in \mathbb{T}}$ and $\left(\hat{S}_{t}^{D}\right)_{t \in \mathbb{T}^{D}}$ denote the regime process of the two Markov-switching models. In doing so, let:

$$
p_{t}^{0}=\mathbb{P}\left(\hat{S}_{t}=0 \mid \boldsymbol{r}_{t} ; \hat{\boldsymbol{\theta}}_{t}\right)
$$

denote the filtered probability of the normal state at time $t$, and let:

$$
p_{t}^{D, 0}=\mathbb{P}\left(\hat{S}_{t}^{D}=0 \mid \hat{S}_{t}=1 ; \boldsymbol{r}_{t} ; \hat{\boldsymbol{\theta}}_{t}\right)
$$

specify the conditional probability of a turbulent state with positive expected return. Then,

$$
p_{t}^{1}=\left(1-p_{t}^{0}\right) \cdot p_{t}^{D, 0} \text { and } p_{t}^{2}=\left(1-p_{t}^{0}\right) \cdot\left(1-p_{t}^{D, 0}\right)
$$

Based on this approach, [12] derive three regimes for the S\&P 500 by considering $\left(S_{t}\right)_{t=1, \ldots, T}$ with $S_{t}=0$ if $\hat{S}_{t}=0, S_{t}=1$ if $\hat{S}_{t}^{D}=0 \wedge \hat{S}_{t}=1$ and $S_{t}=2$ if $\hat{S}_{t}^{D}=1 \wedge \hat{S}_{t}=1$. Their final classification is illustrated in Figure 1. The characteristics of each regime are summarized in Table 1. Regarding the classification of the S\&P 500 index, we clearly observe that the most recent turbulent periods, i.e., the burst of the dot-com bubble, as well as the subprime crisis, have been identified. Due to the additional distinction within the turbulent periods, (turbulent) bullish and (turbulent) bearish phases can be separated. Referring to Figure 1, after a market downturn in a high volatile environment with mainly negative returns, often, some kind of recovery takes place, i.e., high volatile periods offering mainly positive returns can be observed. Focusing on skewness and kurtosis, we observe that the calm period has a slightly negative skewness and the turbulent period a stronger negative skewness, which is due to the turbulent negative period. The turbulent positive period has a positive skewness. Reflecting the kurtosis, the relatively high kurtosis of the turbulent period is reduced by distinguishing in a positive and a negative turbulent state. Although from a return and standard deviation perspective, the calm and turbulent positive periods may look rather similar, both phases have rather different skewness and kurtosis, which supports the introduction of three market periods in the further analysis.

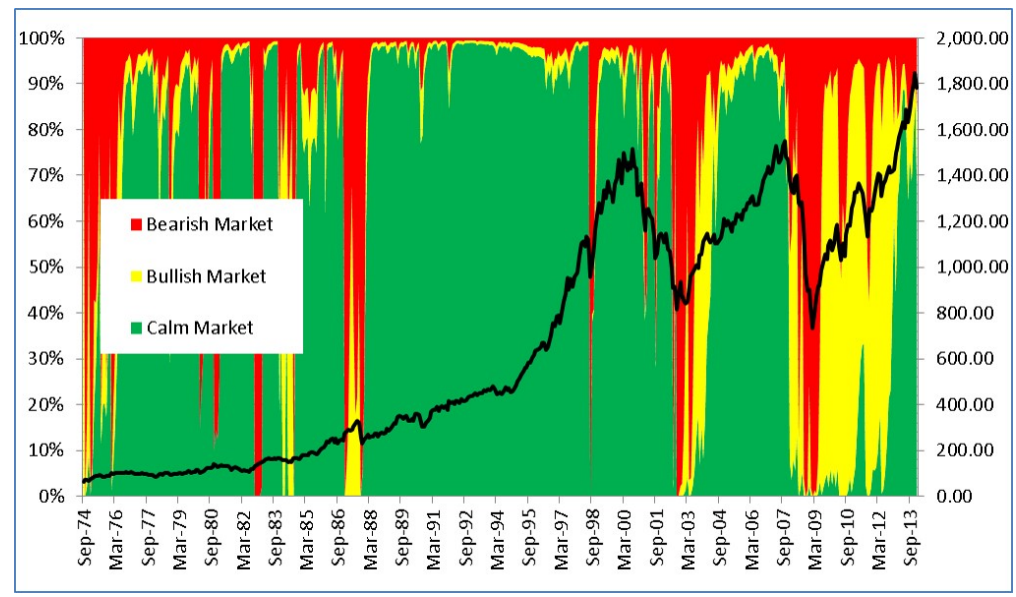

Figure 1. Classification of the S\&P 500 regimes based on two Markov-switching models with two states each. The approach of [12] detects a calm state (green), a turbulent state with mainly negative returns (bearish, red) and a turbulent state with mainly positive returns (bullish, yellow). 
Table 1. Sample characteristics of the monthly returns of the S\&P 500 price index in the three states derived from the two two-state Markov-switching models [12].

\begin{tabular}{ccccc}
\hline S\&P 500 & Calm & Turbulent & $\begin{array}{c}\text { Turbulent } \\
\text { Positive }\end{array}$ & $\begin{array}{c}\text { Turbulent } \\
\text { Negative }\end{array}$ \\
\hline Mean (in \%, ann.) & 10.50 & -2.92 & 12.78 & -19.89 \\
Standard deviation (in \%, ann.) & 13.39 & 20.44 & 15.36 & 22.18 \\
Skewness & -0.08 & -0.50 & 0.20 & -0.49 \\
Kurtosis & 0.15 & 0.87 & 0.52 & 0.48 \\
\hline
\end{tabular}

\subsection{Markov-Switching Model for the Inflation Rate}

In contrast to the S\&P 500 index, a single Markov-switching model with three states proved to be robust for the classification of the inflation rate based on the returns of the Consumer Price Index All Urban (CPI-U) non-seasonally adjusted. Here, a three-state model covers the three main regimes concerning the inflation rate: one state for low inflation (State 1), one state for high inflation (State 3) and a transition state (State 2). Table 2, as well as Figure 2 illustrate the calibrated Markov-switching model for the inflation rate. We clearly observe that in low (State 1) and high inflation (State 3) regimes, the skewness is negative, whereas in the transition state (State 2), the skewness is positive. With respect to the kurtosis, we observe that the kurtosis is significantly decreasing from State 1-State 3.

Table 2. Sample characteristics of the monthly inflation rate in the three states derived from the one three-state Markov-switching model.

\begin{tabular}{cccc}
\hline Inflation & State 1 & State 2 & State 3 \\
\hline Mean (in \%, ann.) & 2.68 & 3.58 & 8.14 \\
Standard deviation (in \%, ann.) & 0.95 & 0.92 & 1.32 \\
Skewness & -1.77 & 0.60 & -0.77 \\
Kurtosis & 15.32 & 5.87 & 1.67 \\
\hline
\end{tabular}

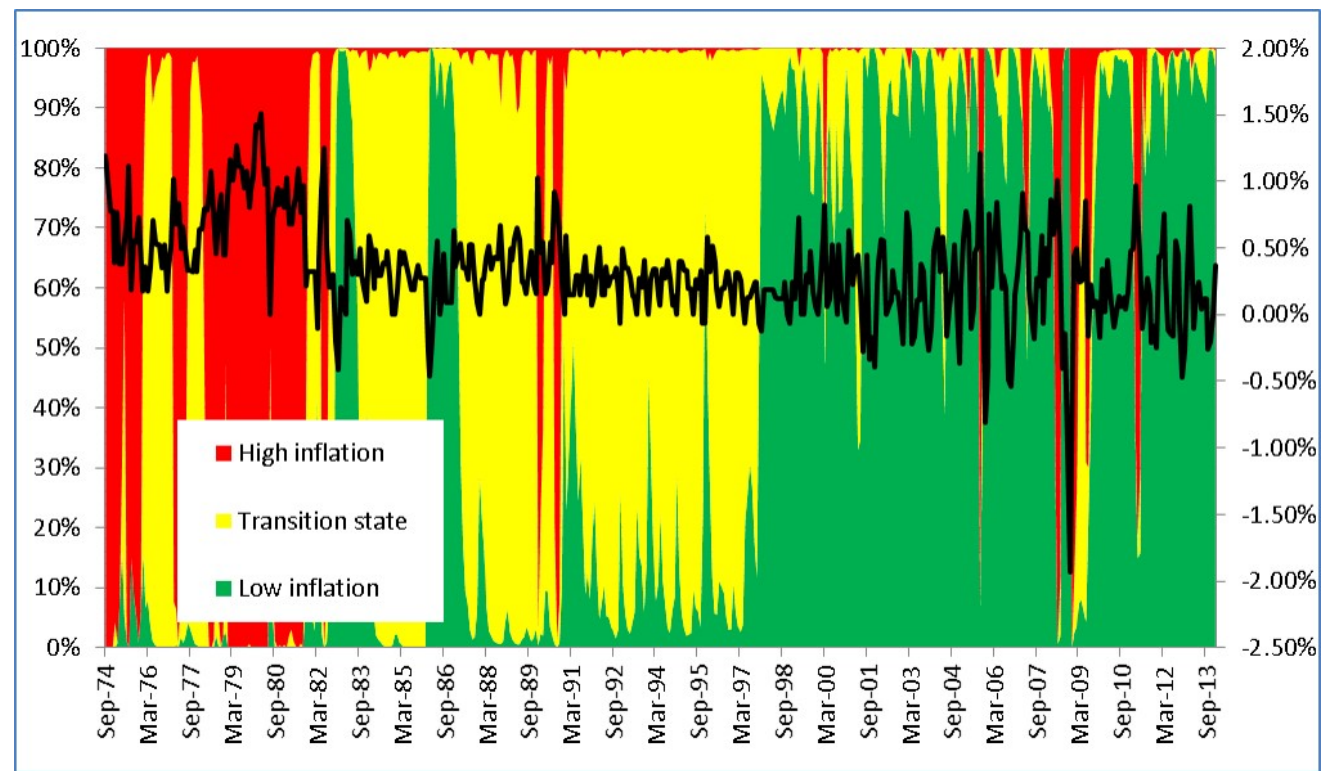

Figure 2. Classification of the inflation regimes based on a Markov-switching model with three states. We detect a calm inflation state (green), a high inflation state (red) and a transition inflation state (yellow). 
Regarding the classification of the inflation rate, the first oil crisis (1973-1974), as well as the second oil crisis (around 1978) are identified as periods in which inflation has been very high (State 3). Additionally, the First Gulf War (1990), as well as Hurricane Katrina (2005) and a short period within the financial crisis (2008) are also characterized as State 3. On the other side, the period starting in 1983 during the Savings-and-Loan crisis is rather supposed to be part of State 2, i.e., of the transition state. The late 1990s, as well as the early 2000s are lastly an example for a period that has been dominated by a low inflation environment. Although, we observe some short peaks in the high inflation regime lately.

\subsection{Markov-Switching Model for Inflation Rate and SEP 500}

In the previous subsections, the inflation rate, as well as the market index (S\&P 500) have both independently been separated into three regimes. In the following, we combine both classification results to separate the dataset into nine different regimes according to the states of the inflation indicator and the market indicator. For the ease of exposition, we first sort the nine regimes by the state of the market indicator and then by the state of the inflation. We set:

- $\quad$ Market calm

- Regime 1: Inflation low, market calm

- Regime 2: Inflation in transition, market calm

- Regime 3: Inflation high, market calm

- Market turbulent-bearish

- Regime 4: Inflation low, market turbulent-bearish

- Regime 5: Inflation in transition, market turbulent-bearish

- Regime 6: Inflation high, market turbulent-bearish

- Market turbulent-bullish

- Regime 7: Inflation low, market turbulent-bullish

- Regime 8: Inflation in transition, market turbulent-bullish

- Regime 9: Inflation high, market turbulent-bullish

Figure 3 gives an overview of the regime movements over time. Clearly, we observe a clustering of regimes with a calm market state, and it is shown that extreme regimes with a critical inflation and market state occur less frequently, but are still not unlikely.

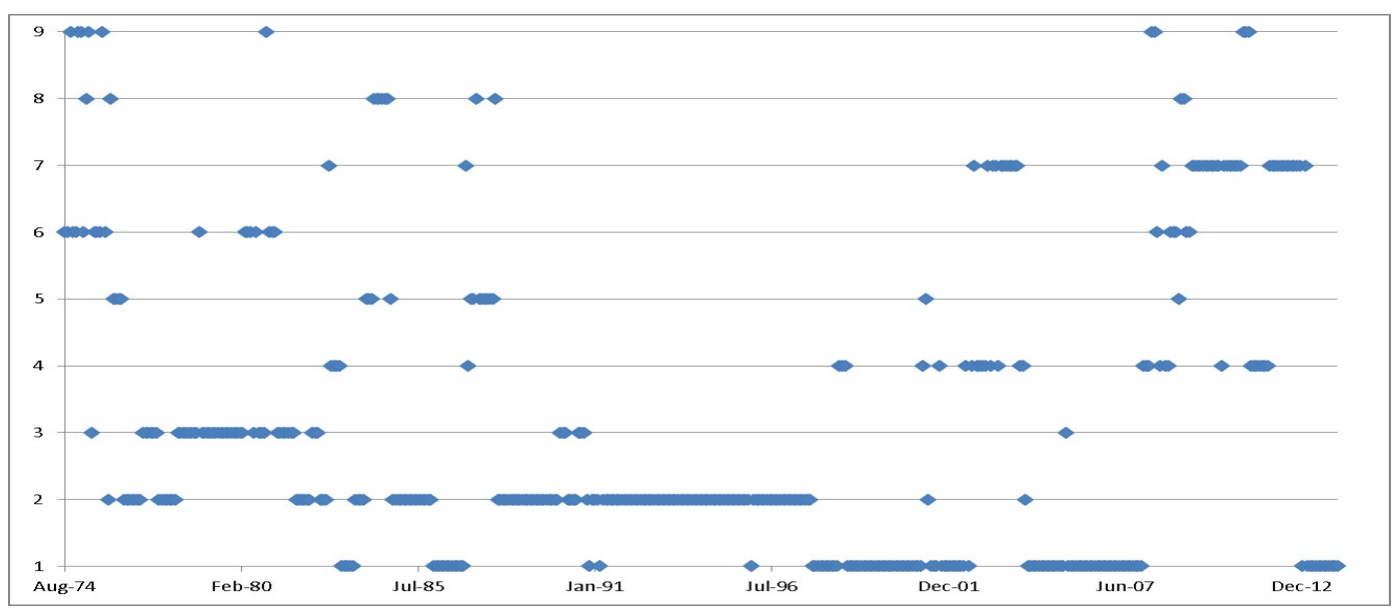

Figure 3. Overview of the separation into 9 regimes over the investigated period.

Table 3 summarizes the regime changes over one time step, i.e., one month. It is seen that most likely, there will be no regime change. Additionally, the observations of Figure 3 are also reflected in 
this table. To be more specific, between two months, mainly one regime (either the market state or the inflation state) has changed if there is a regime change at all. More interestingly, by focusing on the inflation state, there most likely have only been switches from the low inflation to the inflation transition state and from the high inflation state to the inflation transition state. This strengthens the three-regime approach for the inflation rate and also gives an economical interpretation of State 2 to be a transition state.

Table 3. Summary of regime changes.

\begin{tabular}{cccccccccc}
\hline From/to & $\mathbf{1}$ & $\mathbf{2}$ & $\mathbf{3}$ & $\mathbf{4}$ & $\mathbf{5}$ & $\mathbf{6}$ & $\mathbf{7}$ & $\mathbf{8}$ & $\mathbf{9}$ \\
\hline $\mathbf{1}$ & 112 & 4 & 1 & 6 & 0 & 0 & 2 & 0 & 0 \\
$\mathbf{2}$ & 7 & 138 & 5 & 0 & 1 & 0 & 1 & 1 & 0 \\
$\mathbf{3}$ & 1 & 5 & 41 & 0 & 0 & 4 & 0 & 0 & 1 \\
$\mathbf{4}$ & 4 & 1 & 0 & 18 & 2 & 1 & 7 & 0 & 1 \\
$\mathbf{5}$ & 0 & 3 & 0 & 0 & 11 & 0 & 0 & 4 & 0 \\
$\mathbf{6}$ & 0 & 1 & 4 & 1 & 1 & 11 & 1 & 1 & 3 \\
$\mathbf{7}$ & 2 & 0 & 0 & 8 & 0 & 0 & 34 & 1 & 0 \\
$\mathbf{8}$ & 0 & 1 & 0 & 0 & 3 & 1 & 0 & 6 & 1 \\
$\mathbf{9}$ & 0 & 0 & 1 & 1 & 1 & 0 & 0 & 0 & 4 \\
\hline
\end{tabular}

Tables 4 and 5 show average returns and standard deviations in the different regimes. By focusing on the return perspective and by additionally considering the market state, we see that there is not a single asset class with an average return that is always higher than the average inflation rate. Hence, there is (based on monthly data) no asset class that can permanently be used as a hedge against inflation.

Table 4. Average return in different regimes (monthly data, in \%).

\begin{tabular}{cccccccccc}
\hline Regime & $\mathbf{1}$ & $\mathbf{2}$ & $\mathbf{3}$ & $\mathbf{4}$ & $\mathbf{5}$ & $\mathbf{6}$ & $\mathbf{7}$ & $\mathbf{8}$ & $\mathbf{9}$ \\
\hline Inflation & 0.21 & 0.31 & 0.74 & 0.27 & 0.14 & 0.52 & 0.26 & 0.12 & 0.53 \\
Stocks & 0.93 & 1.06 & 0.54 & -1.08 & -0.39 & -0.39 & 1.75 & 2.18 & 4.25 \\
Real Estate & 0.27 & 0.30 & 0.35 & 0.32 & 0.32 & 0.33 & 0.19 & 0.63 & 0.24 \\
Gold & -0.32 & 0.49 & 2.16 & 1.31 & 0.94 & 1.16 & 0.52 & 0.74 & 2.22 \\
Bonds & 0.49 & 1.03 & 0.66 & 0.86 & 0.70 & 1.05 & 0.66 & -0.91 & -3.51 \\
Com. & 0.34 & 0.66 & 1.89 & 0.58 & -1.92 & 0.59 & 1.29 & 1.47 & -2.54 \\
\hline
\end{tabular}

Table 5. Standard deviations in different regimes (monthly data, in \%).

\begin{tabular}{cccccccccc}
\hline Regime & $\mathbf{1}$ & $\mathbf{2}$ & $\mathbf{3}$ & $\mathbf{4}$ & $\mathbf{5}$ & $\mathbf{6}$ & $\mathbf{7}$ & $\mathbf{8}$ & $\mathbf{9}$ \\
\hline Inflation & 0.28 & 0.24 & 0.36 & 0.16 & 0.26 & 0.39 & 0.28 & 0.36 & 0.58 \\
Stocks & 2.79 & 3.04 & 3.28 & 3.31 & 3.89 & 3.68 & 3.47 & 3.81 & 3.88 \\
Real Estate & 1.25 & 0.07 & 0.11 & 0.15 & 0.12 & 0.13 & 0.54 & 1.29 & 0.17 \\
Gold & 4.57 & 5.01 & 9.45 & 3.94 & 4.27 & 7.40 & 5.16 & 5.99 & 6.86 \\
Bonds & 1.62 & 5.84 & 5.62 & 1.85 & 4.12 & 5.55 & 2.67 & 4.20 & 7.49 \\
Com. & 6.29 & 4.58 & 4.87 & 4.84 & 5.96 & 5.57 & 5.62 & 9.20 & 10.72 \\
\hline
\end{tabular}

Table 6 displays the empirical correlations between the inflation rate and the selected asset classes in different regimes. Not only do the correlations vary significantly, but also the signs of the correlations change between different regimes. Again, commodities are the only asset class that has a positive correlation in every single regime. However, with increasing inflation and a normal or turbulent-bearish market state, the correlation between commodities and inflation decreases. For stocks, the correlation with inflation behaves similarly in normal and turbulent-bearish markets. For 
low and high inflation states, the correlation values are small, and if the inflation is in transition, the correlation with inflation increases moderately. If the market is turbulent-bullish, however, we observe a different picture. For low inflation, the correlation of stocks and inflation is low; if the inflation is in transition, the correlation occurs as more strongly negative; whereas in a high inflation state, the correlation occurs as more strongly positive. Real estate has moderate negative correlation with inflation, except in the case of inflation in transition and a turbulent-bearish market; there, the correlation is moderately positive. Gold has a positive correlation with inflation, except in cases when the inflation is in transition and the market is either calm or turbulent-bullish. Bonds show light positive and negative correlations with inflation. However, if inflation is in transition and the market turbulent-bearish, the positive correlation increases, and if inflation is high and the market turbulent-bullish, the correlation with the inflation yields a higher negative value. This varying behavior in different regimes may be an explanation for the different findings about the correlation between specific asset classes and inflation in the literature as described in Section 2.

Table 6. Correlation with inflation rate in different regimes (monthly data, in \%).

\begin{tabular}{cccccccccc}
\hline Regime & $\mathbf{1}$ & $\mathbf{2}$ & $\mathbf{3}$ & $\mathbf{4}$ & $\mathbf{5}$ & $\mathbf{6}$ & $\mathbf{7}$ & $\mathbf{8}$ & $\mathbf{9}$ \\
\hline Stocks & -2.02 & 9.50 & 2.09 & 2.59 & 17.95 & 5.25 & 1.49 & -35.96 & 41.55 \\
Real Estate & -0.21 & -6.09 & -20.67 & -21.12 & 17.90 & -1.48 & -7.78 & -26.10 & -14.22 \\
Gold & 24.94 & -0.72 & 20.56 & 47.58 & 30.37 & 14.99 & 12.03 & -26.39 & 2.13 \\
Bonds & -5.08 & 0.99 & 1.57 & -6.90 & 28.80 & 1.56 & -7.08 & 2.12 & -39.91 \\
Com. & 66.35 & 33.25 & 5.80 & 54.97 & 39.84 & 21.61 & 63.05 & 75.89 & 62.07 \\
\hline
\end{tabular}

\section{Optimal Portfolios}

In this section, we want to derive optimal portfolios, which include protection from losses due to changing inflation if inflation is rising or high, but decouple their performance from inflation if inflation is low. In the first step, we do this regime by regime and rather think of a one-month horizon. In the second step, we consider longer time horizons and do not assume that the regime is known in advance.

\subsection{Regime-Dependent Optimal Portfolios}

As correlation alone is not a reliable indicator for inflation protection, we follow [5,7] to also include the expected returns of the asset classes, as well as their standard deviations in our decision process. This is done within an optimization problem. According to our goal of protecting a portfolio from losses due to (rising) inflation, we do not only consider the classical mean-variance approach by [37], but also adjust this framework to account for the risk of underperforming inflation within the optimization problem. This leads to the following two investment problems:

Optimization problem "Mean Variance (MV)":

$$
\begin{aligned}
\max f(\mathbf{x}) & =E[r(\mathbf{x})]-\lambda \cdot E\left[(r(\mathbf{x})-E[r(\mathbf{x})])^{2}\right] \\
x & \geq 0
\end{aligned}
$$

Optimization problem "Inflation Protection (IP)":

$$
\begin{aligned}
\max f(\mathbf{x}) & =E[\max \{r(\mathbf{x})-I ; 0\}]-\lambda \cdot E\left[(\max \{I-r(\mathbf{x}) ; 0\})^{2}\right] \\
\bar{r}(\mathbf{x}) & \geq \bar{I} \\
x & \geq 0
\end{aligned}
$$


In both optimization problems, $\mathbf{x}$ represents the portfolio weights, $r(\mathbf{x})$ the portfolio return, $I$ the inflation rate, $\bar{r}(\mathbf{x})$ the expected portfolio return and $\bar{I}$ the expected inflation rate. Obviously, (MV)is the classical mean-variance approach. The Optimization problem (IP)is the modified optimization problem and mainly driven by the aspect that an investor might be interested in a portfolio that behaves similar to the inflation rate whenever inflation is high, but will be rather unhappy with a match with inflation when inflation is low. Therefore, the return component of the optimization problem considers the out-performance of the inflation rate, whereas the risk component is driven by events where inflation has been higher than the portfolio return.

Both optimization problems include the risk aversion parameter $\lambda$. In order to find realistic values for $\lambda$, we apply the following approach: we consider two "benchmark" portfolios, Portfolio 1 consisting of $20 \%$ stocks and $80 \%$ bonds and a more diversified Portfolio 2 consisting of $10 \%$ stocks, $40 \%$ bonds, $10 \%$ gold, $20 \%$ real estate and $20 \%$ commodities. Here, Portfolio 1 is a standard portfolio, and Portfolio 2 is a mix of the two suggested portfolios from [7] for moderate and high inflation, in which we included commodities as additional risky investment and added the suggested cash part to bonds. For these two portfolios, we derive implicit $\lambda$ values by setting the goal function of the optimization problems to zero. To do this, we applied the following simulation scheme to determine 100,000 asset returns and the $\lambda$ values $^{3}$ :

1. Draw randomly in which regime $s_{0}$ we are at the beginning of the simulation. The probabilities are taken from the column sums of the matrix described in Table 3 divided by the sum of all entries.

2. Draw randomly, in which regime $s_{1}$ we are after the next time step, given that we have been in $s_{0}$ before. Here, the conditional probabilities are calculated from the according row of the matrix described in Table 3.

3. Denote by $\hat{r}_{s_{1}}$ and $\hat{\Sigma}_{s_{1}}$ the average return and covariance matrix of all observations that ended up in $s_{1}$. Furthermore, take the average return $\hat{r}_{s_{0}, s_{1}}$ of all observations that changed from $s_{0}$ to $s_{1}$ as an expert view. Combine this expert view with the average return $\hat{r}_{s_{1}}$ by setting:

$$
\bar{r}_{s_{0}, s_{1}}=w \cdot \hat{r}_{s_{0, s_{1}}}+(1-w) \cdot \hat{r}_{s_{1}}
$$

The weight $w$ is given by the relative frequency of the number of changes from $s_{0}$ to $s_{1}$ divided by the sum of the column $s_{1}$ in the matrix described in Table 3 . This procedure was chosen to decrease the dependence on outliers or small sample sizes. Then, a realization for the log returns of the asset classes is drawn from a $\mathcal{N}\left(\bar{r}_{s_{0}, s_{1}}, \hat{\Sigma}_{s_{1}}\right)$ normal distribution.

4. Goto Step 2 as long as the desired number of simulations is not reached.

We applied this simulation scheme for one- and 12-month time horizons and achieved the following range of $\lambda$ values regarding optimization problems (MV)and (IP):

For Portfolio 1, the $\lambda$ values have been 3.0087 for (MV) and 8.6436 for (IP). Portfolio 2 leads to 5.5669 for (MV) and 14.6254 for (IP). We then decided to choose the closest $\lambda$ in 0.25 steps around the average of the values for Portfolio 1 and Portfolio 2 to set up our optimization problems. Thus, we apply $\lambda=4.25$ for optimization problem (MV) and $\lambda=11.75$ for optimization problem (IP).

Recall that the empirical time series is split into the nine regimes. As the first step, the optimization problems (MV) and (IP) are solved for every regime individually. Accordingly, the optimal portfolios in the sequel are an answer to the question: whenever the time series has been in regime $s_{i}$, which portfolio would have been optimal in exactly this regime $s_{i}$ ? Motivated by the transition matrix shown in Table 3, in most of the cases, the regime stays in the current regime

3 The algorithm is applied to avoid inconsistencies in the case of a low number of observed changes from one state to another. Step 3 is usually done before the simulation for all states $s_{0}, s_{1}$ to fill a table from which the average returns are then taken within the simulation process. 
and does not change. Obviously not included at this point are considerations that when we assume that, e.g., the market is calm and the regime switches from high inflation (Regime 3) into a inflation transition (Regime 2), an investor may want to set up a different investment strategy than in the case when the inflation is low (Regime 1) and switches into the transition state (Regime 2). This effect is included later in the simulations to develop optimal portfolios for longer time horizons.

\subsection{Monthly Time Horizon}

Table 7 shows the portfolio weights and the portfolio characteristics in each regime for optimization problem (MV). Table 8 displays the portfolio weights and the portfolio characteristics in each regime for optimization problem (IP).

Table 7. Optimal regime-dependent portfolios (in \%) for problem Mean Variance (MV) (monthly data).

\begin{tabular}{cccccccccc}
\hline Regime & $\mathbf{1}$ & $\mathbf{2}$ & $\mathbf{3}$ & $\mathbf{4}$ & $\mathbf{5}$ & $\mathbf{6}$ & $\mathbf{7}$ & $\mathbf{8}$ & $\mathbf{9}$ \\
\hline \multicolumn{8}{c}{ Portfolio Weights } \\
\hline Stocks & 66.22 & 62.94 & 2.16 & 0.00 & 17.84 & 0.00 & 72.18 & 69.88 & 92.68 \\
Real Estate & 0.00 & 4.01 & 0.20 & 0.00 & 29.55 & 77.99 & 0.00 & 18.79 & 0.00 \\
Gold & 0.00 & 7.51 & 18.88 & 47.02 & 21.23 & 0.00 & 0.00 & 1.53 & 7.32 \\
Bonds & 33.78 & 17.84 & 7.17 & 52.98 & 31.39 & 22.01 & 9.90 & 0.00 & 0.00 \\
Com. & 0.00 & 7.70 & 71.60 & 0.00 & 0.00 & 0.00 & 17.92 & 9.80 & 0.00 \\
\hline \multicolumn{8}{c}{ Portfolio characteristics } \\
Mean & 0.78 & 0.94 & 1.82 & 1.07 & 0.47 & 0.70 & 1.56 & 1.80 & 4.10 \\
SD & 1.87 & 2.32 & 4.18 & 2.09 & 1.45 & 1.90 & 2.79 & 2.80 & 3.54 \\
Inflation & 0.21 & 0.31 & 0.74 & 0.27 & 0.14 & 0.52 & 0.26 & 0.12 & 0.53 \\
\hline
\end{tabular}

Table 8. Optimal regime-dependent portfolios (in \%) for problem (Inflation Protection (IP) (monthly data).

\begin{tabular}{cccccccccc}
\hline Regime & $\mathbf{1}$ & $\mathbf{2}$ & $\mathbf{3}$ & $\mathbf{4}$ & $\mathbf{5}$ & $\mathbf{6}$ & $\mathbf{7}$ & $\mathbf{8}$ & $\mathbf{9}$ \\
\hline \multicolumn{10}{c}{ Portfolio Weights } \\
\hline Stocks & 95.51 & 70.22 & 0.00 & 0.00 & 6.87 & 0.00 & 86.84 & 42.56 & 87.84 \\
Real Estate & 0.00 & 0.00 & 0.00 & 0.00 & 0.00 & 12.92 & 0.00 & 4.88 & 0.00 \\
Gold & 0.00 & 0.00 & 22.61 & 100.00 & 50.08 & 0.00 & 0.00 & 7.86 & 12.16 \\
Bonds & 4.49 & 19.82 & 29.85 & 0.00 & 43.05 & 63.12 & 0.00 & 0.00 & 0.00 \\
Com. & 0.00 & 9.96 & 47.55 & 0.00 & 0.00 & 23.96 & 13.16 & 44.71 & 0.00 \\
\hline \multicolumn{10}{c}{ Portfolio characteristics } \\
\hline Mean & 0.91 & 1.01 & 1.59 & 1.31 & 0.47 & 1.36 & 1.69 & 1.68 & 4.01 \\
SD & 2.65 & 2.61 & 3.98 & 3.94 & 2.46 & 4.13 & 3.15 & 4.31 & 3.35 \\
Inflation & 0.21 & 0.31 & 0.74 & 0.25 & 0.14 & 0.52 & 0.26 & 0.12 & 0.53 \\
\hline
\end{tabular}

As we can see, the optimal portfolios weights in the individual regimes are quite different. First, we discuss the optimal portfolios when the market is in a normal state. Regarding Regime 1, the mean-variance optimization problem (MV) leads to a stock-bond portfolio in a 2:1 ratio, whereas the inflation-adjusted optimization problem (IP) is a stock-dominated portfolio with a small portion of bonds. In Regime 2, the mean-variance approach leads to an almost constant stock position of $62.94 \%$; the bond portion is reduced; and gold, commodities and real estate are added. Compared to the corresponding inflation-optimization problem, the stock portion is reduced to $70.22 \%$; the bonds investment is increased; and $9.96 \%$ commodities are included. Here, commodities replace parts of the stocks due to the fact that commodities have a much higher correlation with inflation in this regime. By looking at Regime 3, there is a bigger difference between the two portfolios. The inflation-adjusted setting has commodities as the main portfolio component with $47.55 \%$, and the rest is split into bonds and a smaller portion of gold. The mean-variance approach is dominated with $71.60 \%$ by commodities, has a comparable gold portion as the (MV) portfolio and only a small portion 
of bonds, $7.17 \%$. The high expected returns of these two asset classes and the positive correlation of commodities and inflation in Regime 3 are the reason for this portfolio composition.

Now, we look at the optimal portfolios in the case of a turbulent-bearish market. In Regime 4, the (IP) portfolio consists completely of gold, and the (MV) is a split between bonds and gold; in Regime 5, $50.08 \%$ of the (IP) portfolio are gold and $43.05 \%$ bonds, and a small stock portion is added, as well. The (MV) portfolio is more diversified, with portfolio weights of $20 \%-30 \%$, and only commodities are excluded. Commodities are excluded due to there negative return in this regime. The other asset classes, gold, bonds and real estate, have a return that is higher than the inflation rate and have been appropriate candidates for the optimal portfolios. The small stock portion in the (IP) portfolio can be explained by diversification effects. In Regime 6, gold leaves both portfolios. The (IP) portfolio is dominated by bonds, has a small real estate portion and a larger commodities portion. The (MV) portfolio is dominated by real estate and has in addition $22.01 \%$ bonds.

Lastly, we switch to the case when the market is turbulent-bullish. In Regime 7, both portfolios are dominated by stocks. In the (IP) case, only commodities are added; the (MV) portfolio adds commodities and bonds. In Regime 8 , we observe an equal split between stocks and commodities and small portions of real estate and gold for the (IP) setting, whereas the (MV) portfolio is still dominated by $69.88 \%$ of stocks and is completed with $18.79 \%$ real estate, $9.80 \%$ commodities and $1.53 \%$ gold. In this regime, stocks have a negative correlation with inflation and commodities a strong positive correlation with inflation. This explains why commodities are more strongly included in the (IP) portfolios due to the optimization problem. In Regime 9, stocks, as well as commodities are positive correlated with inflation; for the optimal portfolios, both are strongly stock dominated, and a small gold portion is added to the portfolios. Here, commodities have not been selected as a portfolio component.

It is interesting to note that the asset classes bonds, commodities, gold and real estate are used to protect the portfolio from losses in inflation if inflation is high. If inflation is low or moderate, stocks, bonds and commodities dominate the optimal portfolios.

A clear advantage of our approach is the distinction of inflation, as well as market regimes. Especially, an investigation of the optimal inflation-protected portfolios from Table 8 allows us to take a deeper look at the short-term (monthly) hedging properties of our investigated asset classes. Regarding stocks, e.g., $[2,20]$ state that stocks do not have hedging potential in the short run, and by looking at the regimes with a high inflation state (Regimes 3 and 6), we observe that stocks are indeed not included in the optimal portfolio, except for the case that the market is turbulent-bullish (Regime 9). Thus, in times of high inflation and a normal or turbulent-bearish market, stocks are not a good choice for an optimal inflation-protected portfolio. However, else if stocks are not in a turbulent-bearish state and/or the inflation is not in a high state, we observe that stocks play an important role in the inflation-protected portfolio. Regarding real estate, we observe that it is hardly included in the case of a calm market (Regimes 1, 2 and 3). In turbulent-bearish markets (Regimes 4, 5 and 6) real estate has for the (IP) portfolios a minor role in the case of a high inflation state (Regime 6), whereas in the (MV) case, real estate has an important role in the case of inflation in transition (Regime 5) and is the dominant portfolio weight in the case of high inflation (Regime 6). Especially in the case of real estate, it becomes clear that the consideration of the market environment is crucial, and that mixed statements in the literature in favor of real estate $([2,28]$ or $[25])$, as well as against real estate as an inflation hedge ([34]) can be explained.

When the market is not turbulent-bearish, the gold portion of the portfolio increases comparing low inflation, inflation in transition and high inflation (Regime 1->2->3 and Regime 7->8->9). Thus, as a portfolio component, gold works in these cases as an inflation hedge. However, when the market is in distress, i.e., turbulent-bearish, the (IP) portfolio is gold, and the (MV) portfolio is a split between gold and bonds when the inflation is low (Regime 4). However, the gold portion is halved by taking a look at the inflation in transition optimal portfolios (Regime 5), and finally, in case of high inflation (Regime 6), gold is removed completely from the portfolios. Therefore, gold can be interpreted as a 
hedge against a turbulent-bearish market, but not as hedge against high inflation when the market is turbulent-bearish.

Commodities, on the other hand, are chosen as a hedge against inflation when the market is calm (Regimes 2 and 3) or when the market is in turbulent-bullish and inflation is in transition (Regime 8). For the (IP) portfolio, they are additionally included in the case of high inflation and a turbulent-bearish market (Regime 6). Though, our results are in line with, e.g., [29,30].

With respect to bonds, the general opinion in the literature is that they do not work as an inflation hedge for short time horizons (e.g., [2,17]). Our results show that bonds play hardly any role in turbulent-bullish markets (Regimes 7, 8 and 9). However, due to the negative correlation between bonds and stocks, bonds are an important portfolio component when the market is in distress (Regime 4, 5 and 6). When the market is calm (Regimes 1, 2 and 3), bonds are included in the portfolios, but compared to other portfolios components, they are in these cases not the return drivers of the portfolio.

Summing up, for general statements about short-term inflation-hedging properties of stocks, real estate, gold, commodities and bonds, it is crucial to incorporate the inflation regime, as well as the market regime. As the last step in this subsection, we take a look at the selection of the optimal portfolios over time. Therefore, the classification of S\&P 500 and the inflation rate is done on a monthly basis. Here, we included for the classification of month $i$ only the data history until month $i$. Then, we followed the investment idea, that if month $i$ is in regime $s$, also the following month $i+1$ will be in regime $s$. As optimal portfolios, we have selected the according (IP) portfolios from Table 8, and Figure 4 illustrates the optimal portfolios over time. Analogously, we have taken the according (MV) portfolios from Table 7, and the portfolio decomposition is shown in Figure 5.

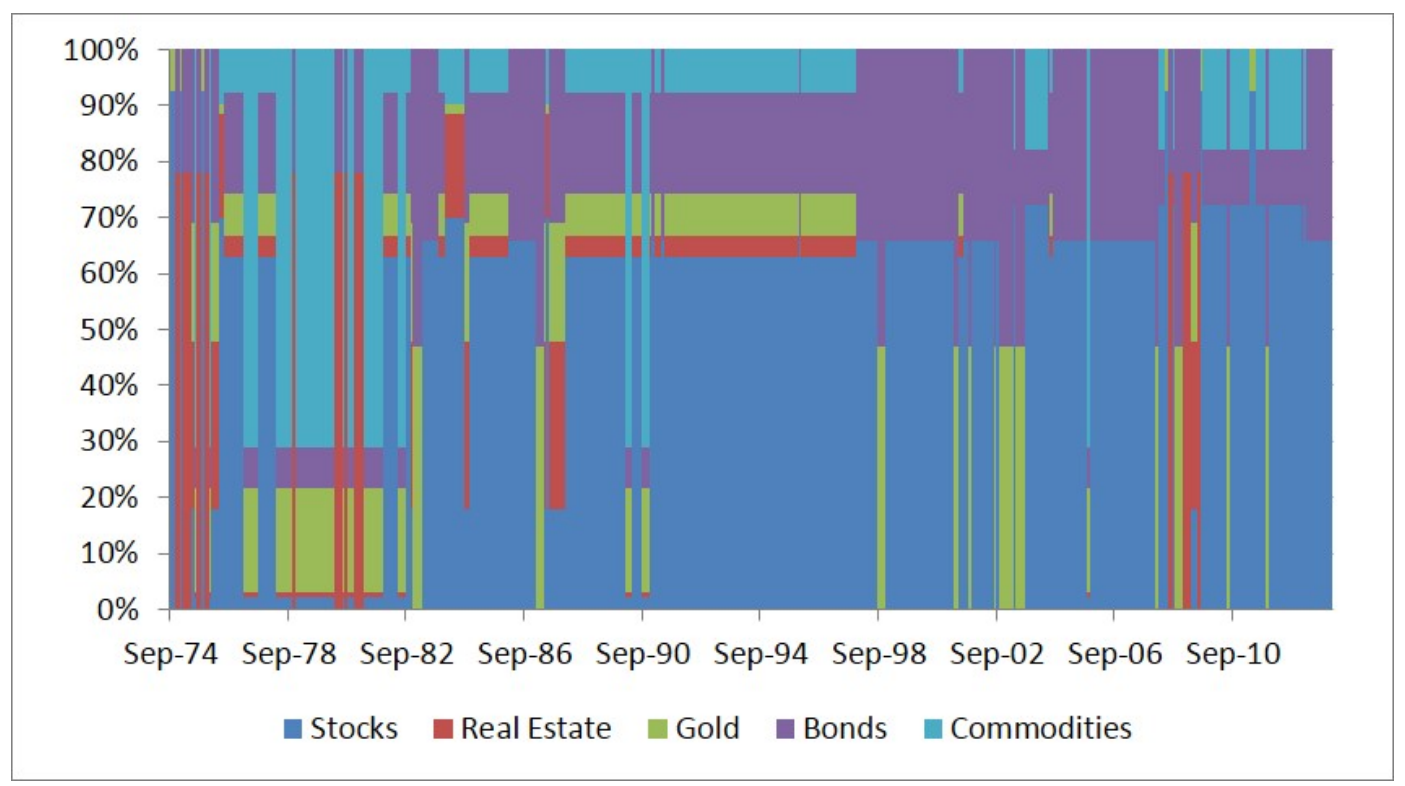

Figure 4. Overview of selected (IP) portfolios over time assuming that the current regime will also be the regime of the next month. 


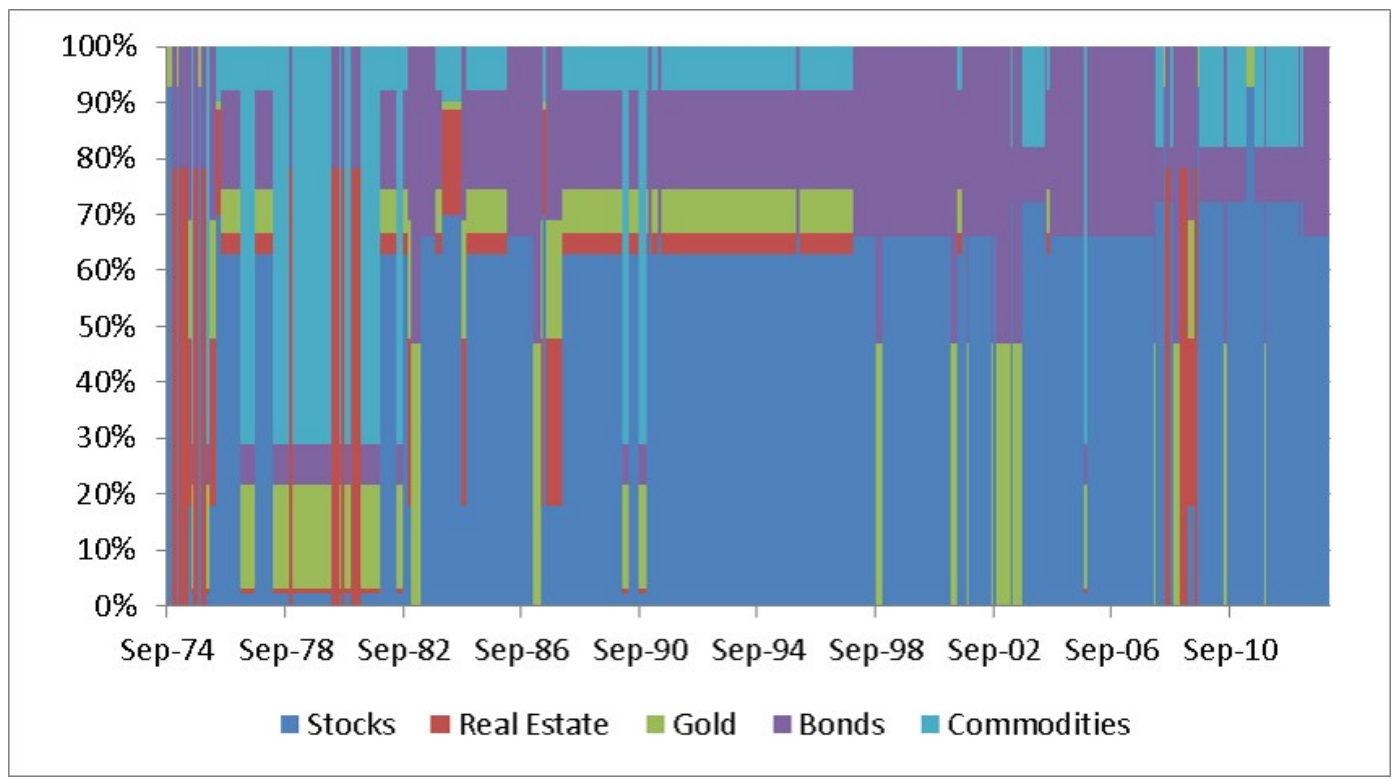

Figure 5. Overview of selected (MV) portfolios over time assuming that the current regime will also be the regime of the next month.

This procedure allows us to take a look at the performance of our (IP) portfolio during several crises and to compare it to other portfolios. As benchmarks, we used the mean variance (MV) portfolio, applying the similar strategy to the optimal portfolios from Table 7 , and a $50 \%$ stock $/ 50 \%$ bond portfolio, as well as an equally-weighted so-called $\frac{1}{N}$-portfolio. Tables 9 and 10 as well as Figure 6 show the results. By looking at the performance over the whole time period, the (IP) portfolio and the (MV) portfolio show strong results. This indicates that due to the Markov-switching approach, we do not only achieve protection against negative movements, but also enable the portfolio to use upside potential. When we look at the S\&P 500 rally from December 1987 until March 2000, we see that our portfolios have an acceptable performance, although in these cases, the benchmark strategies are slightly better. During the second oil crisis (January 1979-June 1980), the early 1980s recession (July 1981-November 1982), the First Gulf War (August 1990-March 1991), Hurricane Katrina and the aftermaths (August-December 2005) and the financial crisis (July 2007-June 2009), we observe that in each crisis, the (IP) portfolio outperforms the inflation rate, as illustrated in Table 10. We clearly see that the (MV) portfolio does not beat the inflation rate in the early 1980s recession. This follows directly from the optimization approach. The (MV) problem does not link the performance to the inflation rate, whereas the (IP) portfolio directly considers the inflation rate. The performance of the $50 \%$ stock $/ 50 \%$ bond portfolio is not linked to the inflation rate at all, and thus, the performance depends mostly on the market regime. Lastly, we take a look at the $\frac{1}{N}$-portfolio. Here, we see that often, diversification seems to be a key element for the portfolio decomposition. In all crises, the performance of the portfolio exceeds the inflation rate, but at least during the First Gulf War, it exceeds the inflation rate only slightly. Thus, diversification itself may not guarantee an inflation-protected portfolio. Additionally, we see that during every crisis, except for the early 1980s recession, the performance of the (IP) portfolio is higher than the $50 \%$ stock $/ 50 \%$ bond portfolio and the $\frac{1}{N}$-portfolio. For a risk-adjusted perspective, we include in Table 9 the standard deviation, the Sharpe ratio, the Omega and the maximum drawdown for the strategies over the whole period, as in Figure 6 and in Tables 11 and 12, for different crises periods. As a benchmark for the Sharpe ratio and the Omega, we used the inflation rate. Thus, the Sharpe ratio and Omega are derived considering the monthly excess returns of the investment strategies over the inflation rate. Focusing on the whole period, we observe that the (MV) portfolio has the highest Sharpe ratio and highest 
Omega, closely followed by the (IP) portfolio. Nevertheless, the higher volatility of the (IP) portfolio leads to the highest maximum drawdown, which can be traced back to the time period from March 2002-October 2006, in which the minimum was obtained in September 2004. For individual crisis periods, we observe a mixed picture. Due to strong diversification effects of the $\frac{1}{N}$-portfolio and the high percentage of bonds in the $50 \%$ stock $/ 50 \%$ bond portfolio, the standard deviation of these portfolios is usually lower than in the (IP) and (MV) portfolios. This results in a generally higher maximum drawdown in the (IP) and (MV) portfolios. The (IP) portfolio has, except for the early 1980s recession and Katrina, a Sharpe ratio and an Omega in a comparable region to the highest according values, and during the First Gulf War, the (IP) portfolio has the highest Sharpe ratio.

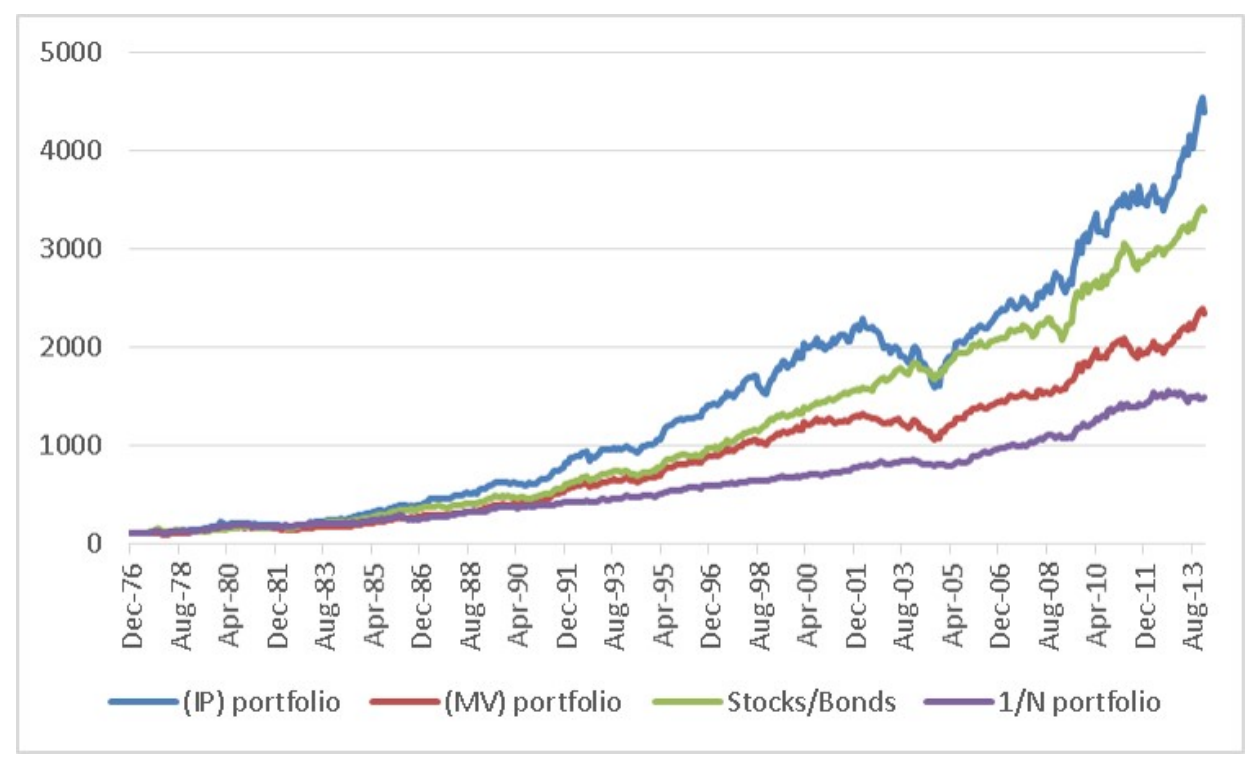

Figure 6. Comparison of the portfolio movements of the different strategies.

Table 9. Overview of mean, standard deviation and the risk measures Sharpe ratio, Omega and maximum drawdown (in \%; the benchmark is the inflation rate) over the whole time horizon for the strategies, as in Figure 6.

\begin{tabular}{ccccc}
\hline & (IP) Portfolio & (MV) Portfolio & Stocks/Bonds & $\frac{1}{N}$-Portfolio \\
\hline Mean & 0.85 & 0.71 & 0.79 & 0.61 \\
Standard deviation & 3.05 & 2.60 & 2.60 & 2.06 \\
Sharpe ratio & 16.03 & 16.82 & 14.08 & 11.39 \\
Omega & 155.13 & 160.32 & 150.74 & 136.43 \\
Maximum Drawdown & -31.09 & -25.14 & -24.86 & -17.80 \\
\hline
\end{tabular}

Table 10. Overview of the performance (in \%) of the (IP) and (MV) portfolios during several periods and crises.

\begin{tabular}{|c|c|c|c|c|c|c|c|c|c|}
\hline \multirow{2}{*}{ Period } & \multicolumn{2}{|c|}{ IP-Port. } & \multicolumn{2}{|c|}{ MV-Port. } & \multicolumn{2}{|c|}{ Stocks/Bonds } & \multicolumn{2}{|c|}{$\frac{1}{N}$-Port. } & \multirow{2}{*}{ Infl. } \\
\hline & Mean & SD & Mean & SD & Mean & SD & Mean & SD & \\
\hline 2nd oil crisis & 2.59 & 5.78 & 1.99 & 5.96 & 1.62 & 4.11 & 2.25 & 4.36 & 1.04 \\
\hline Early 1980 s recession & 0.82 & 2.60 & 0.46 & 2.58 & 1.21 & 3.15 & 1.18 & 1.79 & 0.46 \\
\hline First Gulf War & 1.44 & 3.20 & 1.77 & 4.42 & 0.88 & 1.77 & 0.43 & 1.27 & 0.38 \\
\hline S\&P 500 rally 87-00 & 1.01 & 2.50 & 0.98 & 2.21 & 0.91 & 1.87 & 0.62 & 1.41 & 0.21 \\
\hline Katrina & 0.56 & 1.28 & 1.03 & 1.40 & 0.40 & 0.57 & 0.50 & 1.45 & 0.25 \\
\hline Financial Crisis & 0.39 & 2.38 & 0.42 & 1.66 & 0.19 & 1.88 & 0.29 & 1.49 & 0.13 \\
\hline
\end{tabular}


Table 11. Overview of Sharpe ratio, Omega and maximum drawdown (in \%; the benchmark is the inflation rate) during several periods and crises for the (IP) and (MV) portfolios.

\begin{tabular}{cccccccc}
\hline \multirow{2}{*}{ Period } & \multicolumn{3}{c}{ IP-Portfolio } & & \multicolumn{3}{c}{ MV-Portfolio } \\
\cline { 2 - 3 } \cline { 7 - 8 } & Sharpe & Omega & M.D. & & Sharpe & Omega & M.D. \\
\hline 2nd oil crisis & 26.91 & 204.47 & -14.52 & & 16.11 & 151.54 & -15.52 \\
Early 1980s recession & 13.20 & 147.61 & -5.72 & & 0.00 & 100.00 & -6.49 \\
First Gulf War & 34.40 & 254.38 & -3.00 & & 32.50 & 295.51 & -4.03 \\
S\&P 500 rally 87-00 & 27.57 & 211.59 & -10.77 & & 29.92 & 231.94 & -8.40 \\
Katrina & 24.12 & 192.21 & -0.87 & & 54.56 & 585.72 & -0.38 \\
Financial Crisis & 10.84 & 129.92 & -7.65 & & 16.69 & 157.44 & -3.40 \\
\hline
\end{tabular}

Table 12. Overview of Sharpe ratio, Omega and maximum drawdown (in \%; the benchmark is the inflation rate) during several periods and crises for the stock/bond and the $\frac{1}{N}$-portfolio.

\begin{tabular}{|c|c|c|c|c|c|c|}
\hline \multirow{2}{*}{ Period } & \multicolumn{3}{|c|}{ Stocks/Bonds } & \multicolumn{3}{|c|}{$\frac{1}{N}$-Portfolio } \\
\hline & Sharpe & Omega & M.D. & Sharpe & Omega & M.D. \\
\hline 2nd oil crisis & 13.77 & 138.67 & -5.25 & 27.36 & 231.75 & -9.63 \\
\hline Early 1980s recession & 23.00 & 182.64 & -3.64 & 37.59 & 266.50 & -3.14 \\
\hline First Gulf War & 28.61 & 198.55 & -3.23 & 4.53 & 111.01 & -2.23 \\
\hline S\&P 500 rally $87-00$ & 31.45 & 226.27 & -7.50 & 21.91 & 173.87 & -5.46 \\
\hline Katrina & 22.82 & 169.37 & -0.40 & 18.22 & 158.55 & -1.71 \\
\hline Financial Crisis & 3.15 & 108.54 & -9.17 & 11.74 & 135.26 & -3.87 \\
\hline
\end{tabular}

Overall, we conclude that our presented (IP) portfolio provides a strategy to protect the portfolio returns against inflation and to incorporate upside potential. By additionally taking into account the market regime by constructing portfolios with the focus on inflation protection, the resulting portfolios also offer some incorporated protection against market turbulences when the inflation stays low, as seen in the financial crisis. Finally, a comparison to benchmark strategies supports the relevance of the combination of Markov-switching models for the inflation rate, as well as the market indicator to develop inflation-protected strategies.

\subsection{Longer Time Horizons}

Due to the fact that the empirical time series is limited for investigating longer time horizons, simulations are used to create return series for longer time periods. To do this, we apply the following Markov-switching model to the return time series of the different asset classes: the monthly returns are simulated based on the parameters and the transition matrix of the Markov-switching model in order to allow regime switches for the monthly returns as described above in Steps 1-4 on page 12. By focusing on longer time horizons, the transition matrix in Table 3 is considered. Thus, by simulating a 12-month return, the transition probabilities are included, and more importantly, for the asset parameters, it does not only depend in which regime we are in month $i$, it is also considered in which regime we have been in the previous month $i-1$. Recalling the example given in the previous subsection for monthly optimal portfolios, in our simulation, it is a difference if we get into a normal market state with inflation in transition (Regime 2) when the previous month has been in a normal market and high inflation state (Regime 3) or in a normal market and low inflation state (Regime 1); e.g., bond returns could behave differently when we switch from a high inflation into an inflation in transition state than when we switch from a low inflation state into an inflation in transition state. Therefore, in Step 3 of the simulation described on page 12, the average returns of the underlying factors in Regime $i$ depend on the empirical returns whenever Regime $i$ occurs in the time series combined with an expert view reflecting especially the switch from the previous regime into Regime $i$. At this step in our simulation, the Black-Litterman approach allows us to incorporate 
expert views. In this paper, we restricted ourselves to use the empirical observations as expert views. We illustrate this by an example: Assume in our simulation, in month $i$, we are in Regime 3 . At this point, we use for the simulation of the underlying returns not only the parameters estimated on a dataset consisting of all observations when Regime 3 occurred. The transition matrix in Table 3 shows that in 41 cases, the previous month $i-1$ has also been in Regime 3 , but in five cases, the previous month has been in Regime 2; this means the inflation went from a transition into a high inflation state. Additionally, in four cases, the previous month has been in Regime 6, i.e., a high inflation and turbulent-bearish market, and the market went from being turbulent-bearish to being normal. In one case, the market has previously been positive-turbulent (Regime 9), and in one case, the inflation has been in a low inflation state (Regime 1). Summarizing, several paths could have led to being in Regime 3 at month $i$. We could have come from a previous month with a turbulent-bullish or turbulent-bearish market, as well as from a previous month with an already calm market, but inflation in a transition or calm state. Therefore, due to the fact that in our simulation, at each month $i$, the regime of the previous month $i-1$ is known, the estimation of the parameters for the underlying returns in month $i$ is supplemented by an expert view based on the according regime change from the regime $s_{i-1}$ of the previous month to Regime 3.

As the next step, the monthly returns are combined to create returns for investment horizons of 12, 60, 120 and 240 months. For every time horizon, 100,000 returns are calculated. Based on this set of return series, the optimization problems (MV) and (IP) are solved to determine the optimal portfolios. Table 13 contains the optimal portfolios for optimization problem (MV) and Table 14 for optimization problem (IP).

Table 13. Optimal portfolios (in \%) for longer time horizons for (MV).

\begin{tabular}{cccccc}
\hline Asset/Months & $\mathbf{1 2}$ & $\mathbf{6 0}$ & $\mathbf{1 2 0}$ & $\mathbf{1 8 0}$ & $\mathbf{2 4 0}$ \\
\hline \multicolumn{7}{c}{ Portfolio Weights } \\
\hline Stocks & 43.83 & 41.47 & 43.13 & 43.86 & 42.48 \\
Real Estate & 18.02 & 21.01 & 19.58 & 20.38 & 20.13 \\
Gold & 7.95 & 6.81 & 7.76 & 6.62 & 7.53 \\
Bonds & 22.63 & 23.02 & 22.32 & 22.28 & 22.98 \\
Commodities & 7.57 & 7.69 & 7.21 & 6.86 & 6.87 \\
\hline \multicolumn{7}{c}{ Portfolio characteristics } \\
\hline Mean & 0.63 & 0.61 & 0.63 & 0.63 & 0.62 \\
SD & 2.01 & 2.00 & 2.03 & 2.03 & 2.02 \\
\hline
\end{tabular}

Table 14. Optimal portfolios (in \%) for longer time horizons for (IP).

\begin{tabular}{cccccc}
\hline Asset/Months & $\mathbf{1 2}$ & $\mathbf{6 0}$ & $\mathbf{1 2 0}$ & $\mathbf{1 8 0}$ & $\mathbf{2 4 0}$ \\
\hline \multicolumn{7}{c}{ Portfolio Weights } \\
\hline Stocks & 57.49 & 58.69 & 63.72 & 57.03 & 56.72 \\
Real Estate & 0.00 & 0.00 & 0.00 & 0.00 & 0.00 \\
Gold & 2.59 & 0.00 & 0.00 & 0.00 & 0.00 \\
Bonds & 27.54 & 37.09 & 36.28 & 42.97 & 43.28 \\
Commodities & 12.38 & 4.21 & 0.00 & 0.00 & 0.00 \\
\hline \multicolumn{7}{c}{ Portfolio characteristics } \\
\hline Mean & 0.71 & 0.73 & 0.75 & 0.75 & 0.74 \\
SD & 2.54 & 2.77 & 2.88 & 2.89 & 2.90 \\
\hline
\end{tabular}

By increasing the time horizon, we see that the mean-variance approach results in diversified portfolios consisting of roughly $43 \%$ stocks, $20 \%$ real estate, $23 \%$ bonds, $7 \%$ gold and $7 \%$ commodities. This portfolio remains relatively stable over time. On the other hand, the inflation-adjusted portfolio leads for a relatively short time horizons to a diversified portfolio consisting of stocks, bonds, gold and commodities with stocks playing the dominant part of the portfolio, while for longer time 
horizons, the portfolio only consists of stocks and bonds with an increasing bond part. Thus, by focusing on an inflation-protected investment strategy, the time horizon is crucial. While gold and commodities are only considered on a short-term horizon, stocks and bonds are used as inflation-protecting assets for longer time horizons. Here, we go hand in hand with the results of $[2,16]$ (stocks) and $[2,17,24]$ (bonds).

\section{Conclusions}

The proposed Markov-switching model can be used for a consistent optimization of portfolios and investment strategies for different market regimes and arbitrary time horizons driven by the investment idea of protection from losses due to changing inflation if inflation is rising or high, but decoupling the performance from inflation if inflation is low. Whereas in the long run, we agree with the general opinion in the financial literature that stocks and bonds are a suitable hedge against inflation, we observe for short time horizons that the hedging potential of each asset class, especially of real estate and commodities, depends strongly on the state of the current market environment. Thus, our approach provides a possible explanation for different statements in the literature regarding the inflation-hedging properties of these asset classes. Additionally, our Black-Litterman approach in the simulation for longer time horizons is able to combine the empirical data with expert views. In this paper, we restricted ourselves to the empirical observations, but the approach can be combined with expert views when, e.g., investors have the assumptions that the behavior of specific asset classes, like bonds, could react differently in the future than they have done in the past. Furthermore, we have shown that inflation-protected portfolios can be constructed with traditional asset classes. As they only need to protect from inflation if it is high or increasing, such portfolios offer an interesting and probably less expensive alternative to inflation-linked products. This is especially important in light of other problems with these products, like, e.g., fixed time horizons, default risk of the issuing company and giving up of upside potential in calm periods. As a step for further research, a forecasting model for the inflation regime of the upcoming month could be developed analogously to what [12] did for the stock market.

Acknowledgments: We thank the KPMG Center of Excellence in Risk Management for their support. Furthermore, the authors gratefully acknowledge the comprehensive feedback of three anonymous referees, which significantly improved this paper.

Author Contributions: These authors contributed equally to this work.

Conflicts of Interest: The authors declare no conflict of interest.

\section{References}

1. Zhang, A.; Korn, R.; Ewald, C.O. Optimal management and inflation protection for defined contribution pension plans. Blätter DGVFM 2007, 28, 239-258.

2. Hoevenaars, R.P.M.M.; Molenaar, R.D.J.; Schotman, P.C.; Steenkamp, T.B.M. Strategic Asset Allocation with Liabilities: Beyond Stocks and Bonds. J. Econ. Dyn. Control 2008, 32, 2939-2970.

3. Spierdijk, L.; Umar, Z. Are Commodities a Good Hedge Against Inflation-A Comparative Approach; Netspear Discussion Paper 11/2010-078; Available online: http://dx.doi.org/10.2139/ssrn.1730243 (accessed on 25 March 2016).

4. Bodie, Z. Common Stocks as a Hedge Against Inflation. J. Financ. 1976, 31, 459-470.

5. Schürmann, C.; Böschen, M.; Reimann, A. Was in den Krisen des vergangenen Jahrhunderts seinen Wert hielt, womit Sparer am Ende Vermoegen verspielten. Wirtschaftswoche 2010, 20, 34-38.

6. Lester, A.; Santiago, K. Aiming at a Moving Target. JP Morgan 2009, 1, 1-44.

7. Capital Immer schoen weiteratmen. Capital 2010, 8, 27-29.

8. Ernst, C.; Grossmann, M.; Hoecht, S.; Minden, S.; Scherer, M.; Zagst, R. Portfolio selection under changing market conditions. Int. J. Financ. Serv. Manag. 2009, 4, 48-63.

9. Maheu, J.; McCurdy, T. Identifying bull and bear markets in stock returns. J. Bus. Econ. Stat. 2000, 1, 100-112. 
10. Hauptmann, J.; Zagst, R. Identifying bull and bear markets in stock returns. In Enterprise Risk Management; Springer: Berlin, Germany, 2011; pp. 321-338.

11. Bernhart, G.; Höcht, S.; Neugebauer, M.; Neumann, M.; Zagst, R. Asset correlation on turbulent markets and the impact of different regimes on asset management. Asia-Pac. J. Oper. Res. 2011, 1, 1-23.

12. Hauptmann, J.; Hoppenkamps, A.; Min, A.; Ramsauer, F.; Zagst, R. Forecasting market turbulences using regime-switching models. Financ. Mark. Portf. Manag. 2014, 28, 139-164.

13. Mahlstedt, M.; Zagst, R. Inflationsgeschützte Investmentstrategien. Risiko Manag. 2015, 21, 7-14.

14. US Departement of the Treasury. Treasury Inflation-Protected Securities; Available online: https://www. treasurydirect.gov/instit/annceresult/tipscpi/tipscpi.htm (accessed on 25 March 2016).

15. Campbell, J.Y.; Shiller, R.J. Stock Prices, Earnings and Expected Dividends. J. Financ. 1988, 43, 661-676.

16. Ely, D.P.; Robinson, K.J. Are stocks a hedge against inflation? International evidence using a long-run approach. J. Int. Money Financ. 1997, 16, 141-167.

17. Schotman, P.C.; Schweitzer, M. Horizon sensitivity of the inflation hedge of stocks. J. Empir. Financ. 2000, 7, 301-315.

18. Lothian, J.R.; McCarthy, C.H. Equity Returns and Inflation: The Puzzlingly Long Lags. Res. Bank. Financ. 2001, 2, 149-166.

19. Ahmed, S.; Cardinale, M. Does Inflation Matter for Equity Returns? J. Asset Manag. 2005, 6, $259-273$.

20. Campbell, J.Y.; Viceira, L.M. The Term Structure of the Risk-Return Tradeof. Financ. Anal. J. 2005, 61, 34-44.

21. Spyrou, S.I. Are Stocks a Good Hedge Against Inflation? Evidence from Emerging Markets. Appl. Econ. 2004, 36, 41-48.

22. Fama, E.F.; Schwert, G.W. Asset Returns and Inflation. J. Financ. Econ. 1977, 5, 115-146.

23. Fama, E.F. Stock Returns, Real Activity, Inflation, and Money. Am. Econ. Rev. 1981, 71, 545-565.

24. Campbell, J.Y.; Viceira, L.M. Who Should Buy Long- Term Bonds? The American Economic Review 2001, 91, 99-127.

25. Amenc, N.; Martellini, L.; Ziemann, V. Alternative Investments for Institutional Investors: Risk Budgeting Techniques in Asset Management and Asset-Liability Management. J. Portf. Manag. 2009, 35, 94-110.

26. Greer, R.J. Conservative Commodities: A Key Inflation Hedge. J. Portf. Manag. 1978, 4, $26-29$.

27. Bodie, Z. Commodity Futures as a Hedge Against Inflation. J. Portf. Manag. 1983, 31, 459-470.

28. Froot, K.A. Hedging Portfolios with Real Assets. J. Portf. Manag. 1995, 21, 60-77.

29. Gorton, G.; Rouwenhorst, K.G. Facts and fantasies about commodity futures. Financ. Anal. J. 2006, 62, 47-68.

30. Attié, A.P.; Roache, S.K. Inflation Hedging for Long-Term Investors; IMF Working Paper; Available online: https://www.imf.org/external/pubs/ft/wp/2009/wp0990.pdf (accessed on 25 March 2016).

31. Bekaert, G.; Wang, X. Inflation risk and the inflation risk premium. Econ. Policy 2010, 25, 755-806.

32. Beckmann, J.; Czudaj, R. Gold as an inflation hedge in a time-varying coefficient framework. N. Am. J. Econ. Financ. 2013, 24, 208-222.

33. Rubens, J.H.; Bond, M.T.; Webb, J.R. The Inflation-Hedging Effectiveness of Real Estate. J. Real Estate Res. $1989,4,45-56$.

34. Adrangi, B.; Chatrath, A.; Raffiee, K. REIT Investments and Hedging Against Inflation. J. Real Estate Portf. Manag. 2004, 10, 97-112.

35. Hamilton, J. A new approach to the economic analysis of nonstationary time series and the business cycle. Econometrica 1989, 2, 357-384.

36. Baum, L.E.; Petrie, T.; Soules, G.; Weiss, N. A maximization technique occuring in the statistical analysis of probabilitistic functions of markov chains. Ann. Math. Stat. 1970, 41, 164-171.

37. Markowitz, H. Portfolio selection. J. Financ. 1952, 1, 77-91.

(C) 2016 by the authors; licensee MDPI, Basel, Switzerland. This article is an open access article distributed under the terms and conditions of the Creative Commons by Attribution (CC-BY) license (http:/ / creativecommons.org/licenses/by/4.0/). 